\title{
In vitro rearing of stingless bee queens and their acceptance rate into colonies
}

\author{
Charles Fernando dos Santos, Patrick Douglas de Souza dos Santos, \\ Betina BLochteIN

\begin{abstract}
Departamento de Biodiversidade e Ecologia, Faculdade de Biociências, Pontifícia Universidade Católica do Rio Grande do Sul, Av. Ipiranga, 6681, Porto Alegre, RS, Brazil
\end{abstract}

Received 2 June 2015 - Revised 18 August 2015 - Accepted 29 September 2015

\begin{abstract}
The in vitro rearing of queen bees can improve the management and conservation of pollinator insects. Here, we have developed an in vitro queen-rearing protocol for Plebeia droryana (Apidae, Meliponini). Firstly, we evaluated the amount of food offered naturally to $P$. droryana queen larvae. After, we grafted $P$. droryana larvae onto acrylic plates which were kept in constant darkness at $25^{\circ} \mathrm{C}$ and different relative humidity along larval development. We also compared intertegular distance of $P$. droryana queens reared in vitro and naturally. We then tested whether queens reared in vitro would be accepted into new colonies with older and/ or callow workers. We found that $P$. droryana larvae developed into queens if fed with $66 \mu \mathrm{L}$ of larval food. The survival rate of P. droryana queens was $>75 \%$. The queens reared in vitro are similar in size to naturally produced ones. Finally, colonies only containing callow workers are more likely to accept queens reared in vitro. This queen-rearing technique may improve beekeeping practices in the Neotropical Region.
\end{abstract}

\section{bees / beneficial arthropods / caste determination / crops / pollinators / queen production / virgin queens}

\section{INTRODUCTION}

Bees provide an important ecological service as the main pollinators of wild plants and crops (Kevan and Baker 1983; Klein et al. 2007). However, in current years, native bee populations have declined worldwide, threatening this pollination service (Freitas et al. 2009; Potts et al. 2010). The causes of this decline may include habitat loss and/or fragmentation, intense use of agrochemicals, pathogens, alien bee species and climate change (Freitas et al. 2009; Potts et al. 2010). These pressures may well lead to a global deficit in the availability of pollinators for food production even of honeybees Apis mellifera Linnaeus (Aizen and Harder 2009).

Corresponding author: B. Blochtein, betinabl@pucrs.br Manuscript editor: James Nieh
Thus, this concern becomes even more serious because the main bee species globally responsible for agricultural pollination, $A$. mellifera, is suffering increasing death of its colonies due to colony collapse disorder (VanEngelsdorp et al. 2009). Honeybees therefore cannot be relied on in the future as the most effective pollinators of many crops throughout the planet, and we shall have to depend much more on native bee species for effective pollination (Freitas et al. 2009; Garibaldi et al. 2013; Witter et al. 2015).

Further honeybees, few bee species can be traditionally managed in hives (as bumblebees and stingless bees) or elsewhere (solitary bees) (e.g. Freitas and Pereira 2004; CortopassiLaurino et al. 2006; Velthuis and van Doorn 2006), albeit there are about 20,000 bee species worldwide (Michener 2007). In the Neotropical Region, the stingless bees (Apidae: Meliponini) are an important group of highly eusocial bees that have been identified as a viable alternative which 
may help to mitigate the pollination deficit in many natural and crop systems (Freitas et al. 2009; Garibaldi et al. 2013).

The rearing of stingless bees in hives (meliponiculture) is a highly sustainable activity because beekeepers can work near native forests, as well as help conserve endemic bee species, in order to obtain bees' products (pollen, honey, propolis) and promote effective agricultural pollination (Cortopassi-Laurino et al. 2006; Slaa et al. 2006; Contrera et al. 2011). Stingless bees can add high economic value to crops (Giannini et al. 2015). They have been identified as effective pollinators of fruit, vegetables and seed crops such as tomato, coffee, strawberry, citrus, avocado, onion, cucumber and canola (Heard 1999; Slaa et al. 2006; Witter et al. 2015).

Nevertheless, meliponiculture faces the problem of multiplying hives from core colonies which often hold only a few virgin queens (except Melipona Illiger geuns) for successful colony multiplication (Imperatriz-Fonseca and Zucchi 1995). Therefore, the management and propagation of stingless bee colonies may be greatly compromised because there are not sufficient queens to head new colonies (Jaffé et al. 2015). Thus, the mass rearing of virgin queens may offer a means to overcome the low natural production of virgin queens in most stingless bee genera, and therefore increase the number of new colonies that can be used to restore adequate pollination in natural ecosystems or crops (Cortopassi-Laurino et al. 2006; Contrera et al. 2011; Jaffé et al. 2015).

Queen-rearing techniques for stingless bees are based mainly on the overfeeding of female larvae in vitro (Baptistella et al. 2012; Menezes et al. 2013), since castes determination system in most stingless bee genera depends mainly on trophic factors (Darchen and Delage-Darchen 1971). Female larvae destined to become queens receive more larval food in the bigger (royal) cells than female larvae destined to become workers reared in smaller brood cells (Darchen and DelageDarchen 1971).

Because of the potential of stingless bees as crop pollinators (Heard 1999; Slaa et al. 2006; Garibaldi et al. 2013; Witter et al. 2015) and the large number of species in the taxon (more than 300) (Camargo and Pedro 2013), it would be desirable if queen-rearing techniques could develop most stingless bees and be made available to beekeepers and researchers. To date, we have lesser than five stingless bee species with queenrearing techniques published like Frieseomelitta varia (Lepeletier), Scaptotrigona depilis (Moure) and S. Postica (Latreille) (e.g. Hartfelder and Engels 1992; Baptistella et al. 2012; Menezes et al. 2013).

Here, we tested a queen-rearing method and the introduction of these queens into small colonies for Plebeia droryana (Friese). This stingless bee species is of particular interest because it inhabits a wide geographic range in the Neotropical Region including Argentina, Bolivia, Brazil and Paraguay (Camargo and Pedro 2013). Furthermore, $P$. droryana is one of the few stingless bee species that exhibit diapause during colder periods (lasting at least 3 months) in southern South America (Santos et al. 2014). It demands management and conservation programmes for this species since this diapause behaviour probably makes it more vulnerable to anthropogenic disturbances, such as climate warming, than other stingless bee species that do not face such physiological restrictions (Santos et al. 2015).

\section{MATERIALS AND METHODS}

\subsection{Bees and study area}

All larval P. droryana and larval food were harvested from colonies in the stingless bee apiary of the Laboratory of Entomology at the Pontifícia Universidade Católica do Rio Grande do Sul (PUCRS), Porto Alegre, Brazil, between November 2014 to March 2015.

\subsection{Amount of larval food}

We quantified and compared the amount of larval food in queen brood cells $(n=7)$ with that in worker brood cells ( $n=33$ from three colonies) taken from natural colonies kept in PUCRS's apiary. For this, we used an Eppendorf micropipette $(10 \mu \mathrm{L})$ to calibrate microcapillary tubes $(40 \mu \mathrm{L})$ and used them to collect larval food from individual brood cells. We had to slightly aspirate the microcapillaries because the end 
portion of the larval food mass is pasty due to the higher concentration of pollen grains.

We added an extra $10 \%$ of the same larval food to larvae destined to become queens (following Menezes et al. 2013) in order to ensure sufficient sustenance for the full span of larval queen development and an appropriate size.

\subsection{Queen rearing}

Before commencing the rearing procedure, all tools and equipment were washed with distilled water and then sanitized using ethanol. We then established the larvae as follows:

(a) In the apiary, we chose some populous $P$. droryana colonies with recently built brood combs containing only eggs and larval food. These combs were decapped to allow extraction of the larval food. Other, older brood combs were used as a source of newly hatched larvae, 1-3 days old, for grafting. The age of the larvae was estimated by observing their size and position in the comb. That is, younger larvae were smaller and adjacent to brood cells which contained only eggs.

(b) In the laboratory, we transferred $66 \mu \mathrm{L}$ (see "Results") of previously homogenized larval food to each cavity on acrylic plates with 50 cavities (each $5.8 \mathrm{~mm}$ diameter $\times 7.5 \mathrm{~mm}$ deep, i.e. $198 \mathrm{~mm}^{3}$ ) using a manual pipette $(10-100 \mu \mathrm{L})$.

(c) We performed three rearing assays (trial 1: $n=50$; trial 2: $n=50$; trial 3: $n=100$ larvae) by transferring P. droryana larvae and larval food to the cavities, being careful to retain the original orientation of the larvae seen in the brood cell, i.e. with the spiracles in contact with the air (if this is not carefully arranged the larva can die by asphyxiation). We moved the larvae using a wooden stick tipped with an entomological pin modified into a spoon shape.

(d) The queen-rearing plates were placed into hermetic plastic containers $(7 \times 11 \times 17 \mathrm{~cm})$ and kept in an incubator at $25^{\circ} \mathrm{C}$ (model Luca-161/04, LUCADEMA ${ }^{\circledR}$, São Paulo, Brazil), in constant darkness (0L:24D).

(e) The relative humidity inside the plastic container was maintained between 98 and $65 \%$ during the whole period of larval development using a saturated solution of potassium chloride $(\mathrm{KCl})$ in distilled water as necessary (Table I). Temperature and humidity data were collected using Datalogger devices (model U23-001 HOBO Pro v2, version3.6.2, ONSET ${ }^{\circledR}$, Mato Grosso, Brazil) placed in the plastic containers.

\subsection{Acceptance of queens into new colonies}

We tested whether queens reared in vitro P. droryana would be accepted into new, queenless small colonies $(8.5$ high $\times 10$ wide $\times 10$ long $\mathrm{cm})$. Firstly, we introduced approximately 50 workers of different ages (from callow to foraging bees) from $P$. droryana colonies from our stingless bee apiary, which had queens. Next, we added a single comb containing approximately 100 bees which were close to emergence, $0.20 \mathrm{~g}$ of pollen harvested from A. mellifera, and $2.5 \mathrm{~mL}$ of sucrose, glucose and fructose (GLUCOSUL ${ }^{\circledR}$, Rio Grande do Sul, Brazil) mixed with an equal volume of water.

Finally, we placed three to four empty wax pots $\left(500 \mathrm{~mm}^{3}\right)$ in the corner of the queenless colonies. After 2 days, approximately 7-day-old queens reared in vitro were introduced into these small colonies $(n=20)$, and their behaviour towards the workers was observed. If queens were rejected, this same procedure was repeated (see "Results") using 9-day-old queens reared in vitro $(n=15)$. Virgin queens were considered

Table I. Overall features of the queen-rearing protocol of Plebeia droryana .

\begin{tabular}{|c|c|c|c|c|}
\hline Status & Saturated solution & Temperature $\left({ }^{\circ} \mathrm{C}\right)$ & Humidity (\%) & Days \\
\hline Fedding larvae & No. Distilled water & $25 \pm 0.39$ & $98 \pm 0.26$ & $0 \rightarrow 3$ \\
\hline Fedding larvae & Yes. Distilled water $+\mathrm{KCl}$ & $25 \pm 0.005$ & $90 \pm 0.5$ & $3 \rightarrow 11$ \\
\hline Defectaion larvae & Yes. Distilled water+KCl & $25 \pm 0.25$ & $90 \pm 0.48$ & $11 \rightarrow 19$ \\
\hline Pupae & Yes. Distilled water $+\mathrm{KCl}$ & $25 \pm 0.07$ & $90.5 \pm 0.29$ & $19 \rightarrow 28$ \\
\hline Pigmented pupae & No & $25 \pm 0.1$ & $65 \pm 1.2$ & $28 \rightarrow 35$ \\
\hline
\end{tabular}


to have been accepted if they were still live after at least 1 week, exhibited vibrating wings and trophallaxis with other bees, had accumulated a retinue and were not attacked by workers.

\subsection{Analysis of comparison of the amount of larval food}

Firstly, we employed a Shapiro-Wilk test to evaluate the normality of the data. On discovering that the data were non-parametric ( $W=0.49, P<0.001)$, we used a chi-squared test to compare both groups (queens vs. workers) using the "chisq.test" function provided by a stats package.

\subsection{Analysis of larval queen survival}

To estimate the survival probability of queen larvae until the end of the rearing period, we performed a Kaplan-Meier survival analysis and compared our three trials (rearing 1, 2 and 3; see "Material and methods") using a log-rank test. For this, we used the "ggsurv" function in the GGally package (Schloerke et al. 2014), as well as the "Surv", "survfit" and "survdiff" functions in the survival package (Therneau 2014), and scales package (Wickham 2014).

\subsection{Analysis of queen size}

To discover whether $P$. droryana queens reared in vitro were similar in size to those reared naturally, we randomly sampled 50 queens reared in vitro (rearing $1=15$, rearing $2=15$, rearing $3=20$ ) and compared them with 20 naturally reared queens (virgin or physogastric) in colonies from our apiary. The intertegular distances (ID) of queens were measured using an OLYMPUS ${ }^{\mathbb{B}}$ stereomicroscope (model SZX 7, ZX-TR 30, Miami, USA) and averages calculated for queens reared in vitro and naturally. The value of ID is highly correlated with body size in bees (Cane 1987; Bullock 1999) and provides a reliable measure for our purposes. We then verified the normality of the data using the ShapiroWilk test, as above. Next, we performed a Bartlett test and F-test to compare the homogeny of variances and different variances between two queen groups (in vitro vs. natural), respectively. Finally, we applied a $t$ test using a stats package.

We also checked for power analysis and effect size in order to assess the reliability of the differences and similarities between sample means. For this, we used the "pwr.t2n.test" function from the $p w r$ package (Champely 2012) which is suitable for $t$ tests with independent groups and unequal sample sizes. Used data were as follows: $n 1=50, n 2=20, d=0.8, p=0.05$, power $=\mathrm{x}$, where, $n 1$ and $n 2$ are the number of in vitro and naturally reared queens, respectively, $d$ is the effect size (quantitative measure of the strength of the mean difference), $p$ is the significance level, and power is the statistical power analysis (Champely 2012).

\subsection{Analysis of acceptance of queens}

We evaluated the probability of successful acceptance of $P$. droryana queens reared in vitro into queenless small colonies using an odds ratio test with $95 \%$ confidence interval (CI) in "oddsRatio" function from the mosaic package (Pruim et al. 2015). We then tested any differences in the acceptance rate of virgin queens between colonies containing both callow (nonpigmented and whitish) and old workers vs. callow workers alone, using Pearson's chi-squared test ( $n=9999$; Monte Carlo simulation).

All the data analyses were performed using statistical packages, cited above, plus stats built for the $\mathrm{R}$ program (R Core Team 2014) and, when applicable, the results were visualized using ggplot2 (Wickham 2009), ggtheme (Arnold 2015) and gridExtra (Auguie 2012) packages.

\section{RESULTS}

\subsection{Larval food volume and developmental time}

The amounts of larval food found in the brood cells of natural virgin queens $(60.3 \pm 1.3 \mu \mathrm{L}$ (mean \pm std.dev.)) and workers $(8.39 \pm 0.65 \mu \mathrm{L}$ (mean \pm std.dev.)) were significantly different $\left(X^{2}=40\right.$, $d f=8, P<0.001$ ) (Figure 1). From an initial volume of c.a. $60 \mu \mathrm{L}$, we therefore added $10 \%$ more larval food totalling $66 \mu \mathrm{L}$ offered to every cavity on the queen-rearing plates of $P$. droryana. In vitro reared queen larvae of $P$. droryana consume at least seven times more food than workers. Larval development of queens reared in vitro took approximately 35 days until emergence. The key developmental stages are shown in Figure 2. 


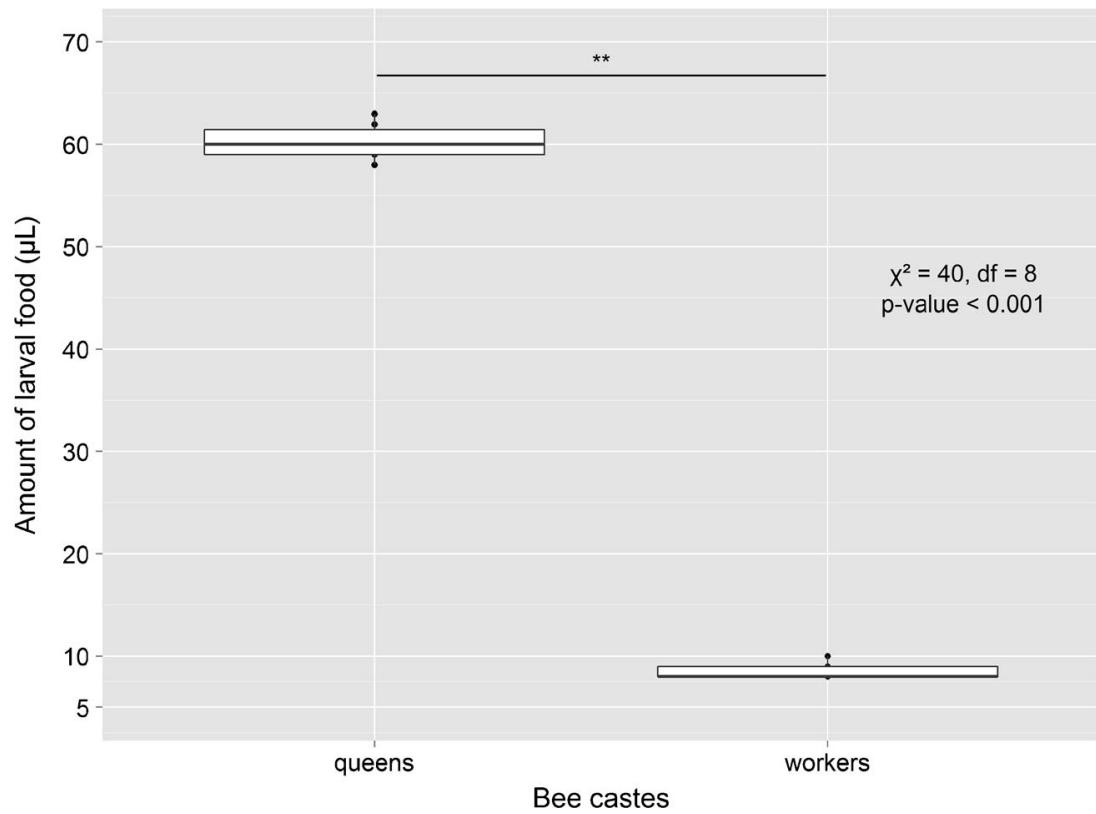

Figure 1. Comparison between the amounts of larval food found in natural brood cells of queens and workers of Plebeia droryana. Boxplot: median, 1st and 3rd quartiles, upper and lower lines indicate the maximum and minimum values. Asterisks indicate significant differences.

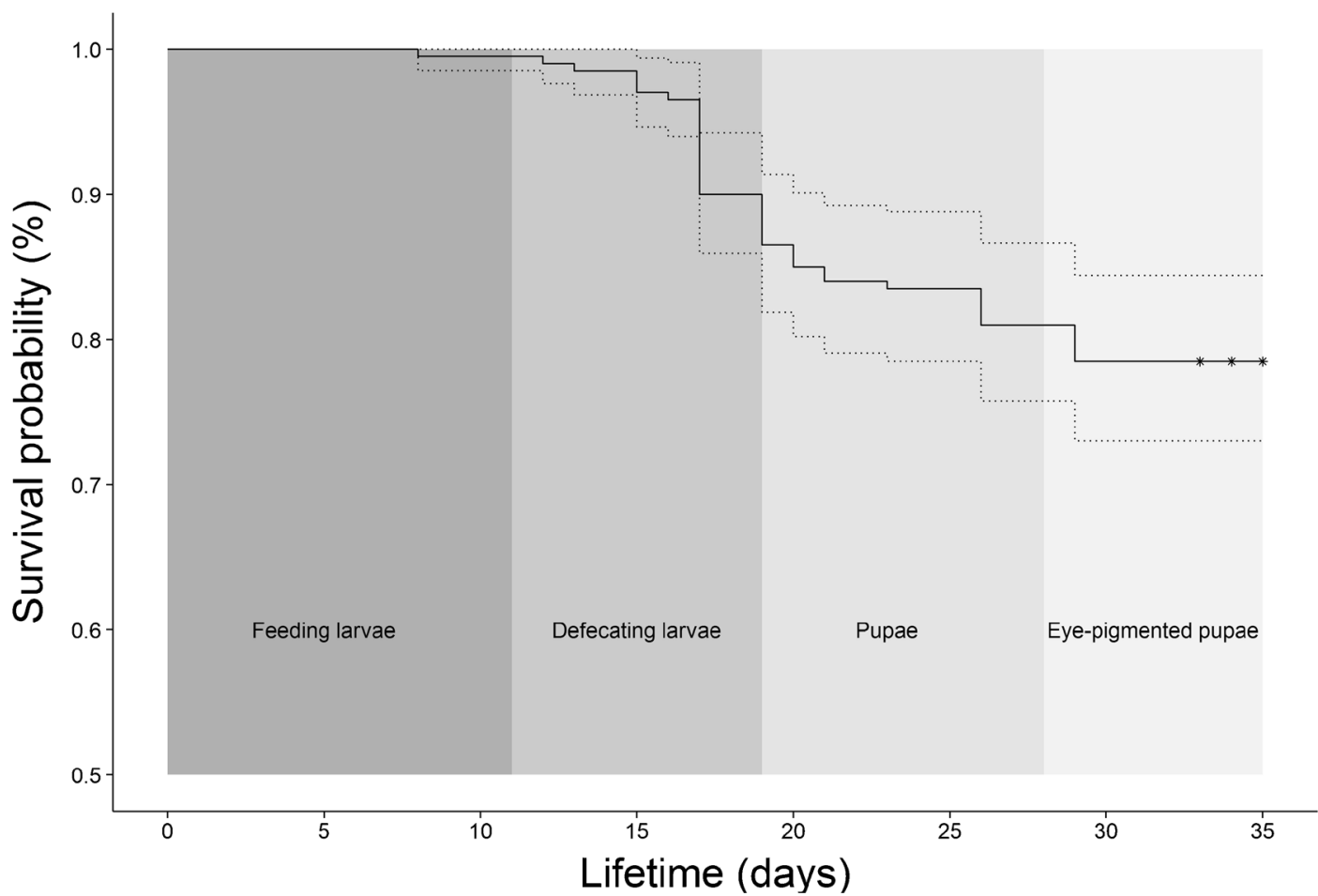

Figure 2. Kaplan-Meier curve (right-censoring) for the average survival probability of Plebeia droryana queens reared in vitro. Note: dotted lines indicate $95 \%$ confidence interval; grey shading indicates average duration time of a particular phase; asterisks indicate adult emergence. 


\subsection{Survival probability of larval queens}

The Kaplan-Meier survival analysis results for each rearing trial (from 1 to 3 ) were, respectively: 0.84 (95\% CI 0.74-0.94), 0.78 (95\% CI 0.670.90 ), and 0.76 (95\% CI 0.68-0.89) (Figure 2). There was no difference between the three rearing trials $\left(X^{2}=1.4, d f=2, P>0.05\right)$. Overall, most larval deaths occurred between the pupal and imago stages, where a loss of $20 \%$ was observed (Figure 2).

\subsection{Queen size}

The Shapiro-Wilk test indicated that the data followed a normal distribution ( $W=0.982$, $P=0.41$ ). However, the Bartlett test showed that the homogeneity of variances were similar (Bartlett's $K$-squared=0.966, $d f=1, P=0.32$ ). Finally, an F-test indicated that variances between samples were not significantly different $(F=0.69$, $P=0.29$ ). We found that the intertegular distances of queens reared in vitro and naturally were similar $(t$ test $=-1.521, d f=68, P=0.132)$ with an overall mean of $1.47 \mathrm{~mm} \pm 0.04$ (mean \pm std.dev.), Figure 3. Finally, our $t$-test power calculation indicated a high power analysis (0.84), giving confidence in the results of our analyses of both queen groups.


\section{DISCUSSION}

Our results indicate that our protocol for rearing $P$. droryana queens in vitro was successful in providing numerous queens over a 35-day period with a high survival probability $(>75 \%)$ of the $P$. droryana larvae until adult queen stage. However, in future, it is needed by paying more attention to the period between the end of larval defecation and the beginning of the pupation phase, the stage where we observed the highest loss of $P$. droryana queen larvae. One possible $t=-1.52, d f=68$ p-value $>0.05$

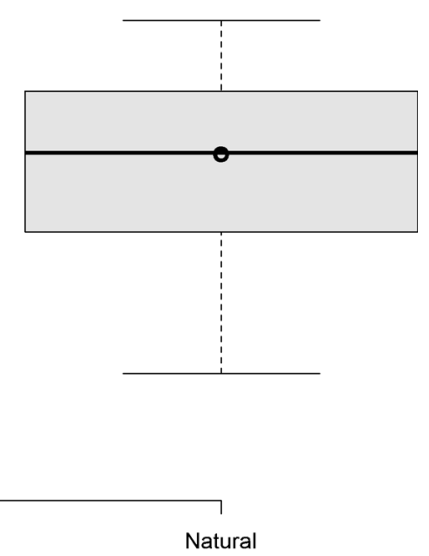

Queens

Figure 3. Comparison of the intertegular distances $(\mathrm{mm})$ between artificially reared (in vitro) and naturally reared Plebeia droryana queens. Boxplot: median, 1st and 3rd quartiles, upper and lower lines indicate the maximum and minimum values; empty circles indicate means. 




Figure 4. Acceptance rate of Plebeia droryana queens reared in vitro inside queenless small colonies containing only callow workers (younger and whitish bees) or with callow and older (i.e. foraging) workers.

improvement would be to alter the temperature and/or relative humidity during this critical period.

The size of $P$. droryana queens reared in vitro was similar to those reared naturally showing that the $10 \%$ extra larval food added to larvae destined to become queens is sufficient for queens reared in vitro reach a normal size, as observed by Menezes et al. (2013). Thus, time can probably be saved in the development of new rearing protocols for other stingless bee species by first assessing the amount of larval food in royal cells and adding $10 \%$ as a baseline practice.

In this study, we show also that the age of workers is an important determinant of successful acceptance of $P$. droryana queens reared in vitro. In practice, only callow workers (non-pigmented) and those brood combs ready to emerge should be chosen for the establishment of new colonies. Thus, the present in vitro queen-rearing method (P. droryana) surely enhances the number of stingless bee species which could be benefit in their management and conservation resulting in higher crop yields.
Although $P$. droryana may not be a species so effective in honey production, this species have other characteristics important that qualify them as good pollinators because they are easy to handle and they are little expensive. For example, its workers are tiny $(3.5-4.7 \mathrm{~mm})$, and its colonies are somewhat enough populous with c.a. 20003000 bees (Santos et al. 2014). In first case, it means that their colonies demand little material to be manufactured beyond if they require less amount of artificial food mainly when small colonial matrices are produced as previously mentioned (see "Material and methods"). Likewise, small colonies enable that hundreds of them are reared side by side on lesser spaces. Furthermore, the large number of bees per colony in $P$. droryana ensures a great amount of forager bees ready to explore and visit cultivated plants inside crops. Finally, $P$. droryana is a species somewhat not aggressive thus implying a secured management to the beekeepers.

In vitro queen rearing of stingless bees is providing in the last years a great strength and practical potentiality (Baptistella et al. 2012; Menezes et al. 2013, this study). However, we have still 
dozens of stingless bee species kept in hives demanding more efforts and technology for a successful management (Cortopassi-Laurino et al. 2006; Contrera et al. 2011; Jaffé et al. 2015). For these bees, the scarcity of queen-rearing methods has been an important technical bottleneck (Cortopassi-Laurino et al. 2006; Jaffé et al. 2015).

Our efforts will continue now on how to successfully inseminate such queens reared in vitro in a secure and instrumental way. Although natural mating could be a possibility, the artificial insemination will provide a controlled fecundation of virgin queens. It may provide better queen selection programmes in order to choose certain features of others.

In summary, human societies are extremely dependent on insect pollinators, mainly bees, to food production (Klein et al. 2007; Garibaldi et al. 2013). But growing global pollination deficit (Aizen and Harder 2009) becomes this unclear scenario. It is known that honeybees (Garibaldi et al. 2013) and likely bumblebees alone cannot supply all of our demands for crop pollination. Stingless bees therefore have a significant role to play in this process because they pollinate such a wide range of cultivated food plants worldwide (Heard 1999; Slaa et al. 2006; Garibaldi et al. 2013; Witter et al. 2015). Queen-rearing techniques for stingless bees can increase the number of bees available for pollination by the more rapid multiplication of colonies. Queen-rearing can also be used in toxicological, biological and evolutionary research, including studies on genetic improvement programmes (queen selection), caste conflict behaviour (workers vs. queens), mating behaviour, native bee conservation and so on.

\section{ACKNOWLEDGMENTS}

We thank the two anonymous referees for the constructive comments to this manuscript. The authors (PDSS, CFS) also acknowledge Fundação de Amparo à Pesquisa do Estado do Rio Grande do Sul (FAPERGS [Proc. $n^{\circ}$ 0684-2551/14-9]) and the Conselho Nacional do Desenvolvimento Científico e Tecnológico (CNPq) [Proc. $\left.{ }^{\circ} 500458 / 2013-8\right]$ for scholarships. We are also grateful to Instituto de Pesquisa e Desenvolvimento (IDEA-PUCRS) for developing rearing plates for our experiments.
Elevage in vitro de reines d'abeilles sans aiguillon et leur taux d'acceptation dans les colonies

\section{Meliponini / cultures / détermination des castes / pollinisateurs / production de reines}

\section{In vitro Aufzucht der Königinnen von Stachellosen} Bienen und deren Annahmeraten in Bienenvölkern

\section{Bienen / Kastendetermination / Kulturpflanzen / Bestäuber / Königinnenproduktion}

\section{REFERENCES}

Aizen, M.A., Harder, L.D. (2009) The global stock of domesticated honey bees is growing slower than agricultural demand for pollination. Curr. Biol. 19,915-918. doi:10.1016/ j.cub.2009.03.071

Arnold, J.B. (2015) ggthemes: Extra themes, scales and geoms for "ggplot2". (R package version 2.2.1) [Computer software]. Retrieved from http://CRAN.Rproject.org/package $=$ ggthemes

Auguie, B. (2015) gridExtra: Miscellaneous functions for "Grid" graphics. (R package version 2.0.0) [Computer software]. Retrieved from https://CRAN.Rproject.org/web/packages/gridExtra

Baptistella, A.R., Souza, C.C.M., Santana, W.C., Soares, A.E.E. (2012) Techniques for the in vitro production of queens in stingless bees (Apidae, Meliponini). Sociobiology 59, 297-310

Bullock, S.H. (1999) Relationships among body size, wing size and mass in bees from a tropical dry forest in Mexico. J. Kansas Entomol. Soc. 72, 426-439

Camargo, J.M.F., Pedro, S.R.M. (2013) Meliponini Lepeletier, 1836. In Moure, J. S., Urban, D. \& Melo, G. A. R. (Orgs). Catalogue of Bees (Hymenoptera, Apoidea) in the Neotropical Region - online version. Available at http://www.moure.cria.org.br/catalogue. Accessed 11 April 2015

Cane, J.H. (1987) Estimation of bee size using intertegular span (Apoidea). J. Kansas Entomol. Soc. 60, 145-147

Champely, S. (2012) pwr: Basic functions for power analysis. (R package Version 1.1.2) [Computer software]. Retrieved from https://CRAN.R-project.org/ web/packages/pwr

Contrera, F.A.L., Menezes, C., Venturieri, G.C. (2011) New horizons on stingless beekeeping (Apidae, Meliponini). Bras. Zootec. 40, 48-51

Cortopassi-Laurino, M., Imperatriz-Fonseca, V.L., Roubik, D.W., Dollin, A., Heard, T., et al. (2006) Global meliponiculture: challenges and opportunities. Apidologie 37, 275-292 
Darchen, R., Delage-Darchen, B. (1971) Le déterminisme des castes les trigones (Hyménoptères Apidés). Insectes Soc. 18, 121-134

Freitas, B.M., Pereira, J.O.P. (2004) Solitary Bees: conservation, rearing and management for pollination, $1 \mathrm{st}$ edn. Imprensa Universitária da Universidade Federal do Ceará, Fortaleza

Freitas, B.M., Imperatriz-Fonseca, V.L., Medina, L.M., Kleinert, A.D.P., Galetto, L., Nates-Parra, G., Quezada-Euan, J.J.G. (2009) Diversity, threats and conservation of native bees in the Neotropics. Apidologie 40, 332-346

Garibaldi, L.A., Steffan-Dewenter, I., Winfree, R., Aizen, M.A., Bommarco, R., et al. (2013) Wild pollinators enhance fruit set of crops regardless of honey bee abundance. Science 339, 1608-16011

Giannini, T.C., Cordeiro, G.D., Freitas, B.M., Saraiva, A.M., Imperatriz-Fonseca, V.L. (2015) The dependence of crops for pollinators and the economic value of pollination in Brazil. J. Econ. Entomol. 1-9. doi:10.1093/jee/tov093

Hartfelder, K., Engels, W. (1992) Allometric and multivariate in the neotropical stingless bee, Scaptotrigona postica. Insectes Soc. 39, 251-266

Heard, T.A. (1999) The role of stingless bees in crop pollination. Annu. Rev. Entomol. 44, 183-206

Imperatriz-Fonseca, V.L., Zucchi, R. (1995) Virgin queens in stingless bee (Apidae, Meliponinae) colonies: a review. Apidologie 26, 231-244. doi:10.1051/ apido: 19950305

Jaffé, R., Pope, N., Carvalho, A.T., Maia, U.M., Blochtein, B., de Carvalho, C.A.L. (2015) Bees for development: Brazilian survey reveals how to optimize stingless beekeeping. PLoS One 10, e0121157. doi:10.1371/ journal.pone.0121157

Kevan, P.G., Baker, H.G. (1983) Insects as flower visitors and pollinators. Annu. Rev. Entomol. 28, 407-453

Klein, A.-M., Vaissière, B.E., Cane, J.H., SteffanDewenter, I., Cunningham, S.A., Kremen, C., Tscharntke, T. (2007) Importance of pollinators in changing landscapes for world crops. Proc. R. Soc. B Biol. Sci. 274, 303-313

Menezes, C., Vollet-Neto, A., Imperatriz-Fonseca, V.L. (2013) An advance in the in vitro rearing of stingless bee queens. Apidologie 44, 491-500

Michener, C.D. (2007) The bees of the world, 2nd ed. Johns Hopkins University Press

Potts, S.G., Biesmeijer, J.C., Kremen, C., Neumann, P., Schweiger, O., Kunin, W.E. (2010) Global pollinator declines: trends, impacts and drivers. Trends Ecol. Evol. 25, 345-353

Pruim, R., Kaplan, D., Horton, N. (2015) mosaic: Project MOSAIC (mosaic-web.org) statistics and mathematics teaching utilities. (R package version 0.10.0) [Computer software]. Retrieved from http://CRAN.Rproject.org/package $=$ mosaic

R Core Team (2014) R: A language and environment for statistical computing. The R Foundation for Statistical Computing, Vienna, Austria. [Computer software]. Retrieved from http://www.R-project.org/

Santos, C.F., Nunes-Silva, P., Halinski, R., Blochtein, B. (2014) Diapause in stingless bees. Sociobiology 61, 369-377. doi:10.13102/sociobiology.v61i4.369-377

Santos, C.F., Acosta, A.L., Nunes-Silva, P., Saraiva, A.M., Blochtein, B. (2015) Climate warming may threaten reproductive diapause of a highly eusocial bee. Environ. Entomol. 44, 1172-1181. doi:10.1093/ee/nvv064

Schloerke, B., Crowley, J., Cook, D, et al. (2014) GGally: Extension to ggplot2. (R package version 0.5.0) [Computer software]. Retrieved from http:/CRAN.Rproject.org/package $=$ GGally

Slaa, E.J., Sánchez-Chaves, L.A., Malagodi-Braga, K.S., Hofstede, F.E. (2006) Stingless bees in applied pollination: practice and perspectives. Apidologie 37, 293-315

Therneau, T. (2014) A package for survival analysis in S. (R package version 2.38) [Computer software]. Retrieved from http://CRAN.R-project.org/ package $=$ survival

VanEngelsdorp, D., Evans, J.D., Saegerman, C., Mullin, C., Hauburge, E., et al. (2009) Colony collapse disorder: a descriptive study. PLoS One 4, e6481. doi:10.1371/ journal.pone.0006481

Velthuis, H.H.W., van Doorn, A. (2006) A century of advances in bumblebee domestication and the economic and environmental aspects of its commercialization for pollination. Apidologie 37, 421-451

Wickham, H. (2009) ggplot2: elegant graphics for data analysis. Springer New York. [Computer software]. Retrieved from http://had.co.nz/ggplot2/book

Wickham, H. (2014) Scales: Scale functions for graphics. (R package version 0.2.5.) [Computer software]. Retrieved from http://CRAN.R-project.org/ package $=$ scales

Witter, S., Nunes-Silva, P., Lisboa, B.B., Tirelli, F.P., Sattler, A., Hilgert-Moreira, S.B., Blochtein, B. (2015) Stingless bees as alternative pollinators of canola. J. Econ. Entomol. . doi:10.1093/jee/tov096 